University of South Carolina

Scholar Commons

1991

\title{
Electrochemical Characterization of Electronically Conductive Polypyrrole on Cyclic Voltammograms
}

\author{
Taewhan Yeu \\ Texas A \& M University - College Station \\ Ken-Ming Yin \\ Texas A \& M University - College Station \\ Jose Carbajal \\ Texas A \& M University - College Station \\ Ralph E. White \\ University of South Carolina - Columbia, white@cec.sc.edu
}

Follow this and additional works at: https://scholarcommons.sc.edu/eche_facpub

Part of the Chemical Engineering Commons

\author{
Publication Info \\ Journal of the Electrochemical Society, 1991, pages 2869-2877. \\ (c) The Electrochemical Society, Inc. 1991. All rights reserved. Except as provided under U.S. copyright law, \\ this work may not be reproduced, resold, distributed, or modified without the express permission of The \\ Electrochemical Society (ECS). The archival version of this work was published in the Journal of the \\ Electrochemical Society. \\ http://www.electrochem.org/ \\ DOI: $10.1149 / 1.2085332$ \\ http://dx.doi.org/10.1149/1.2085332
}

This Article is brought to you by the Chemical Engineering, Department of at Scholar Commons. It has been accepted for inclusion in Faculty Publications by an authorized administrator of Scholar Commons. For more information, please contact digres@mailbox.sc.edu. 


\title{
Electrochemical Characterization of Electronically Conductive Polypyrrole on Cyclic Voltammograms
}

\author{
Taewhan Yeu, ${ }^{*, 1}$ Ken-Ming Yin, ${ }^{* *}$ Jose Carbajal, ${ }^{*, 2}$ and Ralph E. White* \\ Center for Electrochemical Engineering, Department of Chemical Engineering, Texas A\&M University, \\ College Station, Texas 77843-3122.
}

\begin{abstract}
Experimental and theoretical cyclic voltammograms for electronically conducting polypyrrole film are obtained from the identical conditions and compared to each other to characterize electrochemical behavior of the polymer. A comparison of the simulated and experimental cyclic voltammograms shows quantitative agreement. The profiles of the dependent variables show that the switching process is governed by the availability of the counterion to the polypyrrole electrode and the amount of electroactive sites. Sensitivity analysis shows that the double layer effects have more influence in the cyclic voltammograms than the electrokinetic effects.
\end{abstract}

Electronically conductive polypyrroles are an extremely interesting class of materials that have gained popularity in the last decade. It has been accepted that the polypyrrole films have a number of potential technological applications in the areas of energy storage (1-5), solar energy conversion (6-11), and electrochromic display devices (12-15). There is no doubt that polypyrrole is an interesting electrode material. However, the knowledge of electrochemical switching behavior of polypyrrole films published to date remains far from complete. Among those unsettled problems, the electronic and ionic charge transport mechanisms within the polypyrrole films have been fundamentally important since the switching process under most circumstances is controlled by these factors. Thus, an understanding of charge transport within these polymers is a prerequisite to developing further practical applications.

Among the available electroanalytical techniques, the cyclic voltammetry technique has been widely used to understand the electroactivity and the electrochemical properties of polypyrrole films because it can better describe the characteristics of the electrochemical switching behavior between conducting and insulating states (12-19). In this paper, both experimental and theoretical approaches are used.

Experimental cyclic voltammetry is performed for electrochemically synthesized $1 \mu \mathrm{m}$ thick polypyrrole film doped with perchlorate in $1 \mathrm{M} \mathrm{LiClO}_{4}-\mathrm{PC}$ solution. A mathematical model, which is based on the conservation of mass and charged species, the porous electrode theory, the double layer theory, and the modified Butler-Volmer-type pseudo homogeneous electrochemical reaction rate expression, is developed. This model is an extension of previous work published in this laboratory $(20,21)$. Since the electrochemical properties and microscopic structure of polypyrrole film are locally defected, volume-averaged values is used to describe local variables throughout the polymer film to account for the effect of their nonhomogeneity $(20,21)$. The validity of the model is tested by comparing the model predictions to the experimental data.

The model is used to characterize dynamic behavior (i.e., the relationship between microscopic structure, charge transport, and electrochemical characteristics) within the polypyrrole films by studying the profiles of dependent variables. Also, the model is used to verify the interesting parameters to characterize the properties of polypyrrole by sensitivity analysis and studying the effect of each parameter. The efforts to estimate values for the parameters that would yield the best agreement between model predictions and experimental data are included.

\footnotetext{
* Electrochemical Society Active Member.

1Present Address: Duracell USA, Technical Center, Bethel, Connecticut 06801 .

2Present Address: Inland Steel Company, Research Laboratories, East Chicago, Indiana 46312.
}

\section{Experimental Descriptions}

All experiments are carried out in a single-compartment electrochemical cell with the classic three-electrode configuration; a platinum rotating disk electrode as a working electrode, a platinum counterelectrode, and a saturated calomel reference electrode (SCE). A rotating disk electrode ( $R D E$ ) is used here because of its well-defined hydrodynamics $(22,23)$. A Luggin capillary tip of the reference electrode is placed as close as possible to the center of the working electrode surface. This enables one to minimize ohmic loss and to use the reference electrode to detect the solution potential near the working electrode. The system is deoxygenated by nitrogen bubbling throughout experiments.

Electrochemical synthesis is carried out using an EG\&G Princeton Applied Research (PAR) Model 173 potentiostat/galvanostat equipped with a PAR Model 179 digital coulometer. Polypyrrole film is deposited electrochemically on the platinum rotating disk electrode surface at a constant current density of $1 \mathrm{~mA} / \mathrm{cm}^{2}$ in propylene carbonate solution containing $0.1 \mathrm{M} \mathrm{LiClO}_{4}$ and $0.1 \mathrm{M}$ pyrrole monomer. The film thickness is controlled by monitoring the amount of total charge consumed during polymerization. That is, the film thickness is proportional to the total

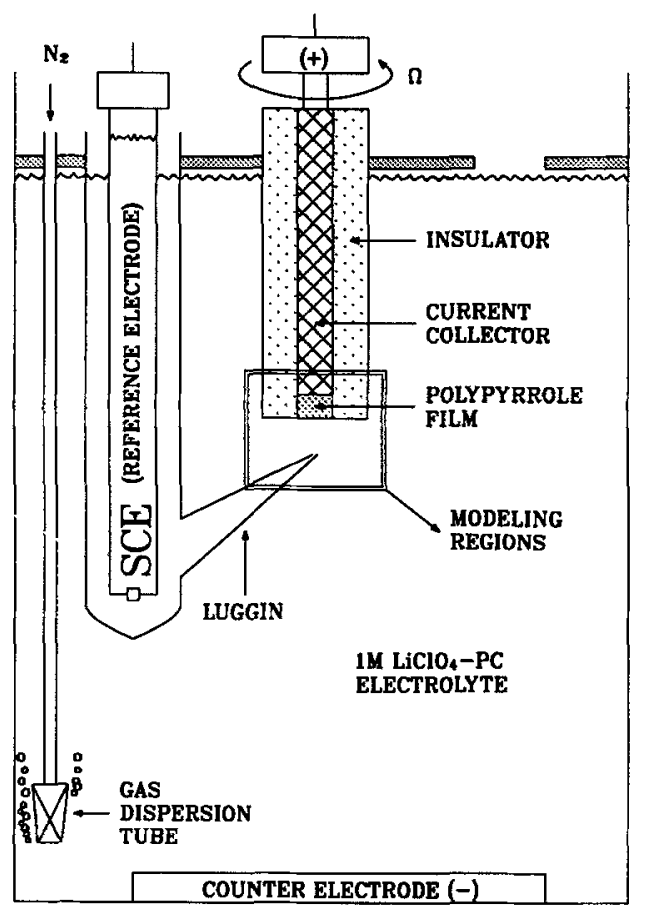

Fig. 1. A schematic diagram of a single-compartment electrochemical cell with a rotating disk electrode. 
passed charge, and $0.24 \mathrm{C} / \mathrm{cm}^{2}$ of passed charge yields $1 \mu \mathrm{m}$ thick polypyrrole film $(18,19)$. The surface of platinum disk electrode is cleaned and polished to a mirror finish with $1,0.3$, then $0.05 \mu \mathrm{m}$ alumina powder (Banner Scientific) on a Metron polishing cloth before polymerization.

After the electrochemical synthesis, the cell is thoroughly rinsed with propylene carbonate and then filled with $1 M \mathrm{LiClO}_{4}-\mathrm{PC}$ electrolyte solution to perform the cyclic voltammetry. Cyclic voltammetry is accomplished using a PAR Model 173 potentiostat/galvanostat in conjunction with a PAR Model 175 programmer, and resulting current density responses are recorded on a Houston Instruments Model 2000 X-Y recorder.

All chemical used are reagant grade (Aldrich Chemicals). Pyrrole is distilled twice in a vacuum and then stored under nitrogen. $\mathrm{LiClO}_{4}$ is used without further purification. The propylene carbonate used as a solvent is further purified by fractional distillation and percolation through activated alumina. The water in the propylene carbonate is removed by adding molecular sieves for a few days. All electrolyte solutions are prepared in a glove box under nitrogen atmosphere.

\section{Model Descriptions}

The model presented here is for predicting the cyclic voltammetric behavior of the polypyrrole films doped with perchlorate. The modeling regions close to the rotating disk electrode, which are relevant to the development of the model equations, are schematically presented in Fig. 2.

The modeling regions consist of two main regions, two boundaries, and one interregional interface, and they must be modeled simultaneously. These are the boundary interface between a platinum current collector and the polypyrrole electrode $(y=0)$; the polypyrrole electrode region of width $\delta_{\text {pp }}$; the inter-regional interface between the polypyrrole electrode and an electrolyte diffusion layer $\left(y=y_{\mathrm{pp}}\right.$; the electrolyte diffusion layer of width $\delta_{\mathrm{dl}}$; and the boundary at a bulk electrolyte solution $\left(y=y_{\mathrm{dl}}\right)$.

In all of the regions, the dependent variables are: the concentration of $\mathrm{Li}^{+}\left(c_{+}\right)$, the concentration of $\mathrm{ClO}_{4}^{-}\left(c_{-}\right)$, the local faradaic charge per unit volume $\left(Q_{f}\right)$, the potential of the solid phase $\left(\Phi_{1}\right)$, and the potential of the solution phase $\left(\Phi_{2}\right)$. Because the cyclic voltammetry is controlled by sweeping potential at a constant scan rate, values for these unknowns depend on the perpendicular distance from the platinum current collector of the polypyrrole electrode $(y)$ and applied potential $(E)$, and they are obtained by solving the system of model equations for each region of the cell simultaneously.

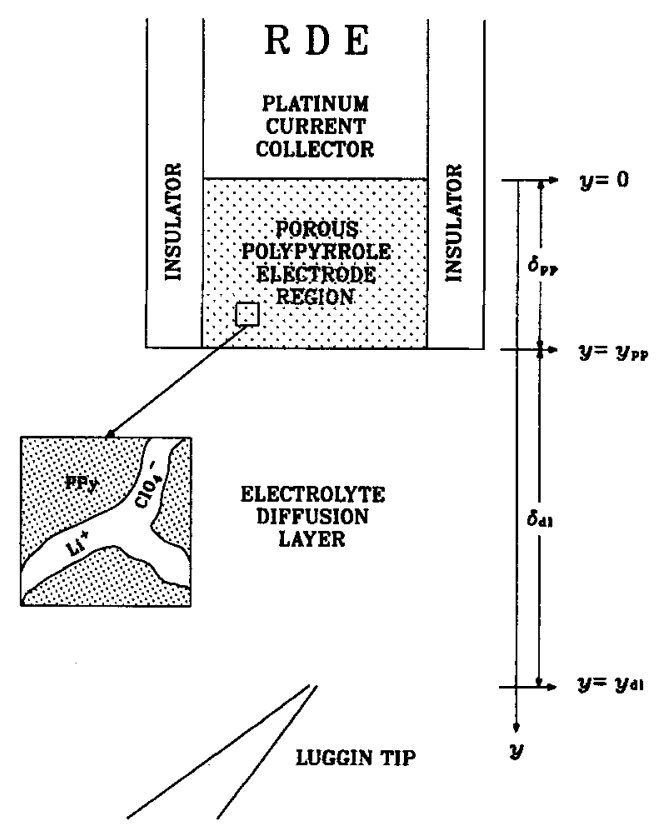

Fig. 2. A schematic diagram of modeling regions closed to the rotating disk electrode in the single-compartment electrochemical cell.
The detailed discussion for the assumptions, mathematical treatment of properties of polypyrrole films, and derivation of the governing equations are given in previous works $(20,21)$. The system of model equations for each region and variable are summarized in Table I.

\section{Results and Discussion}

The values used for the operating conditions in the cyclic voltammograms are given in Table II. The applied po-

Table I. System of model equations for cyclic voltammetry of polypyrrole.

A. Polypyrrole electrode region.

$$
\begin{aligned}
& \text { Variables Governing equations } \\
& \begin{array}{c}
c_{+} \quad \frac{\partial\left(\epsilon_{\mathrm{p}} c_{+}\right)}{\partial t}=z_{+} F \frac{\partial}{\partial y}\left(u_{+, \mathrm{p}} c_{+} \frac{\partial \Phi_{2}}{\partial y}\right)+\frac{\partial}{\partial y}\left(D_{+, \mathrm{p}} \frac{\partial c_{+}}{\partial y}\right)-\frac{s_{+}}{n F} a j \\
c_{-} \quad \frac{\partial\left(\epsilon_{\mathrm{p}} c_{-}\right)}{\partial t}=z_{-} F \frac{\partial}{\partial y}\left(u_{-, \mathrm{p}} c_{-} \frac{\partial \Phi_{2}}{\partial y}\right)+\frac{\partial}{\partial y}\left(D_{-, \mathrm{p}} \frac{\partial c_{-}}{\partial y}\right)-\frac{s_{-}}{n F} a j \\
Q_{\mathrm{f}} \frac{\partial Q_{\mathrm{f}}}{\partial_{t}}=a j \\
\Phi_{1} \\
\Phi_{2}=\frac{\partial j}{\partial y}\left(\sigma_{\mathrm{p}} \frac{\partial \Phi_{1}}{\partial y}\right) \\
\text { Where } a j=a i_{0, \text { ref }}\left\{(1-\theta)\left(\frac{c_{-}}{c_{-, \text {ref }}}\right) \exp \left(\frac{\alpha_{\mathrm{a}} F}{R T} \eta\right)-\theta_{\exp }\left(\frac{-\alpha_{\mathrm{c}} F}{R T} \eta\right)\right\}
\end{array}
\end{aligned}
$$

B. Electrolyte diffusion layer.

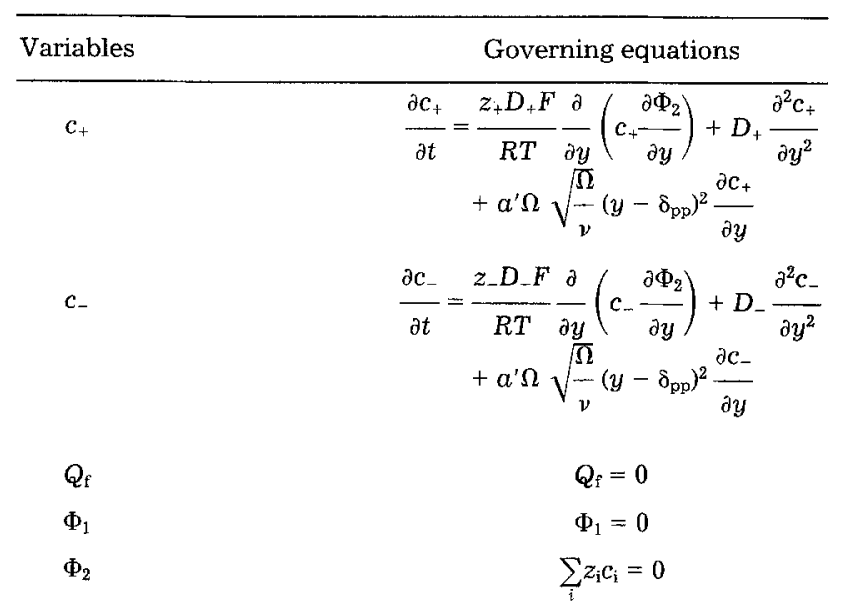

C. Boundary at current collector/polypyrrole electrode.

\begin{tabular}{cc}
\hline Variables & Governing equations \\
\hline$c_{+}$ & $-z_{+} u_{+, \mathrm{p}} F c_{+} \frac{\partial \Phi_{2}}{\partial y}-D_{+, \mathrm{p}} \frac{\partial c_{+}}{\partial y}=-\frac{s_{+}}{n F} a j$ \\
$c_{-}$ & $-z_{-} u_{-, \mathrm{p}} F c_{-} \frac{\partial \Phi_{2}}{\partial y}-D_{-, \mathrm{p}} \frac{\partial c_{-}}{\partial y}=-\frac{s_{-}}{n F} a j$ \\
$Q_{\mathrm{f}}$ & $\frac{\partial Q_{\mathrm{f}}}{\partial t}=a j$ \\
$\Phi_{1}$ & $\Phi_{1}=E+\Phi_{\text {ref }}$ \\
$\Phi_{2}$ & $\frac{\partial \Phi_{2}}{\partial y}-F \sum_{i} z_{\mathrm{i}} D_{\mathrm{i}, \mathrm{p}} \frac{\partial c_{\mathrm{i}}}{\partial y}=0$ \\
Where $a j=a i_{0, \text { ref }}\left\{(1-\theta)\left(\frac{c_{-}}{c_{-, \text {ref }}}\right) \exp \left(\frac{\alpha_{\alpha} F}{R T} \eta\right)-\theta \exp \left(\frac{-\alpha_{\mathrm{c}} F}{R T} \eta\right)\right\}$
\end{tabular}


D. Interface at polypyrrole electrode/diffusion layer.

Variables Governing equations

$$
\begin{aligned}
& c_{+} \quad-z_{+} u_{+, \mathrm{p}} F c_{+} \frac{\partial \Phi_{2}}{\partial y}-D_{+, \mathrm{p}} \frac{\partial c_{+}}{\partial y}=-z_{+} u_{+} F c_{+} \frac{\partial \Phi_{2}}{\partial y}-D_{+} \frac{\partial c_{+}}{\partial y} \\
& c_{-} \quad-z_{-} u_{-, \mathrm{p}} F c_{-} \frac{\partial \Phi_{2}}{\partial y}-D_{-, \mathrm{p}} \frac{\partial c_{-}}{\partial y}=-z_{-} u u_{-} F c_{-} \frac{\partial \Phi_{2}}{\partial y}-D_{-} \frac{\partial c_{-}}{\partial y} \\
&\left.Q_{\mathrm{f}} \quad \frac{\partial Q_{\mathrm{f}}}{\partial y}\right|_{y_{\mathrm{pp}}}=0 \\
&\left.\frac{\partial \Phi_{1}}{\partial y}\right|_{y_{\mathrm{pp}}}=0 \\
& \Phi_{1} \quad \frac{\partial \Phi_{2}}{\partial y}-F \sum_{\mathrm{i}} z_{\mathrm{i}} D_{\mathrm{i}, \mathrm{p}} \frac{\partial c_{\mathrm{i}}}{\partial y}=-\kappa \frac{\partial \Phi_{2}}{\partial y}-F \sum_{\mathrm{i}} z_{\mathrm{i}} D_{\mathrm{i}} \frac{\partial c_{\mathrm{i}}}{\partial y}
\end{aligned}
$$

E. Boundary at bulk solution.

\begin{tabular}{cc}
\hline Variables & Governing equations \\
\hline$c_{+}$ & $c_{+}-c_{+, \text {ref }}$ \\
$c_{-}$ & $c-=c_{-, \text {ref }}$ \\
$Q_{\mathrm{f}}$ & $Q_{\mathrm{f}}=0$ \\
$\Phi_{1}$ & $\Phi_{1}=0$ \\
$\Phi_{2}$ & $\Phi_{2}=\Phi_{\text {ref }}$
\end{tabular}

tential $(E)$ sweeps between -0.8 and $+0.8 \mathrm{~V}$ under the constant scan rates $\left(v_{\mathrm{s}}\right)$ of 10 and $20 \mathrm{mV} / \mathrm{s}$ at room temperature. The scan rate and the potential interval were selected in order to obtain a complete oxidation and reduction of the polymer within the stability range of the electrolyte. The rotating speed of disk electrode $(\Omega)$ is arbitrarily chosen as $3600 \mathrm{rpm}$. A $1 \mu \mathrm{m}$ thick polypyrrole electrode is used in this study because a high doping level and a high efficiency have been observed for this thickness (2). All the potentials were referred to the SCE. The resulting anodic (oxidation) and cathodic (reduction) current densities are specified as being positive and negative, respectively.

Experimental results.-Experimental cyclic voltammograms for a $1 \mu \mathrm{m}$ polypyrrole film in $1 \mathrm{M} \mathrm{LiClO}_{4}$-PC electrolyte at scan rates of 10 and $20 \mathrm{mV} / \mathrm{s}$ are presented in Fig. 3. The $1 \mu \mathrm{m}$ polypyrrole film was deposited on polished platinum disk electrode surface with little difficulty by applying $1 \mathrm{~mA} / \mathrm{cm}^{2}$ for $240 \mathrm{~s}$. Two main considerations can be derived by the analysis of these cyclic voltammograms; well-defined doping-undoping behaviors and large capacitance effects.

The current density is well-defined as positive and negative for doping and undoping processes, and immediately changes sign when the scan is reversed. The electrochromic properties of polypyrrole are clearly demonstrated showing that polypyrrole is actually reduced and oxidized;

Table II. Operating conditions used for cyclic voltammograms of polypyrrole.

Operating temperature $(T)$

Negative potential limit $\left(\boldsymbol{E}_{\text {neg }}\right)$

Positive potential limit $\left(E_{\text {pos }}\right)$

Potential scan rate $(v s)$

Disk rotation velocity $(\Omega)$

Reference electrode potential $\left(\Phi_{\mathrm{re}}\right)$

Geometric electrode surface area $(A$

Thickness of polypyrrole film $\left(\delta_{p p}\right)$

Thickness of electrolyte diffusion layer $\left(\delta_{\mathrm{d} 11}\right)$

Reference concentration of $\mathrm{Li}^{+}(c$

Reference concentration of $\mathrm{ClO}_{4}^{-}\left(c_{-, \text {ref }}\right)$
$298.15 \mathrm{~K}$

$-0.8 \mathrm{~V}$ (vs. SCE)

$+0.8 \mathrm{~V}$ (vs. SCE)

10 and $20 \mathrm{mV} / \mathrm{s}$

$377 \mathrm{rad} / \mathrm{s}$

$0.0 \mathrm{~V}$ (vs. SCE)

$1 \mathrm{~cm}^{2}$

$1 \mu \mathrm{m}$

$0.01 \mathrm{~cm}$

$0.001 \mathrm{~mol} / \mathrm{cm}^{3}$

$0.001 \mathrm{~mol} / \mathrm{cm}^{3}$

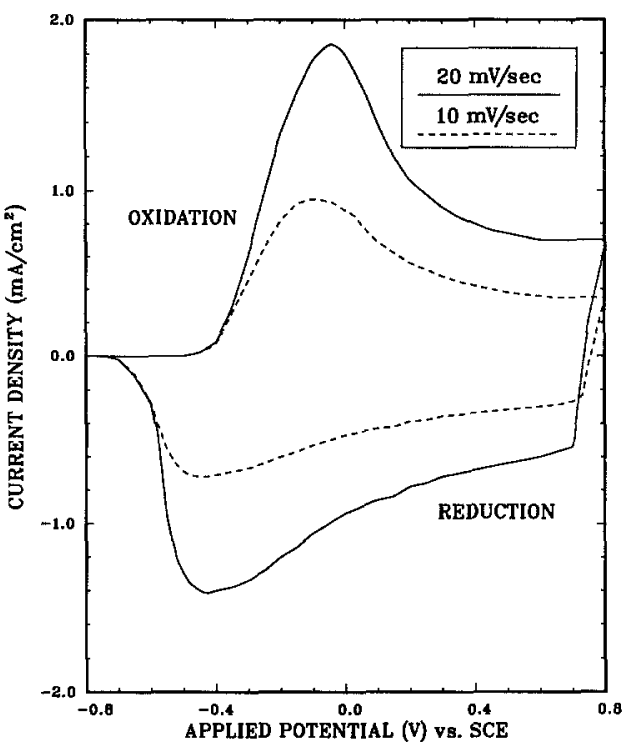

Fig. 3. Experimental cyclic voltammograms for a $1 \mu \mathrm{m}$ polypyrrole film in $1 \mathrm{M} \mathrm{LiClO} 4-\mathrm{PC}$ electrolyte at scan rates of 10 and $20 \mathrm{mV} / \mathrm{s}$.

it is brown-black in the doped state and light yellow in the undoped state. The cyclic voltammograms are not symmetrical but quasi-reversible. The oxidative and reductive charges in each cycle are equivalent to and are independent of the scan rate. The cathodic peaks are significantly broader than the amodic peaks. The peak height is proportional to the scan rate as is expected for a reversible surface process (24). Accordingly, it can be suggested that the elctrochemical behavior in cyclic voltammetry can be explained in relation to the diffusion of counterion. The electrochemical characteristics of the $1 \mu \mathrm{m}$ polypyrrole film in the $1 M \mathrm{LiClO}_{4}-\mathrm{PC}$ electrolyte obtained from these experimental cyclic voltammograms are summarized in Table III.

A large capacitive background current density $\left(i_{\mathrm{c}}\right)$ in the potential region between +0.2 and $+0.8 \mathrm{~V} v s$. SCE (where the film is not oxidized or reduced) is observed and is proportional to the scan rate. The related capacitance, $C_{1}$, may be obtained by simple calculation based on the expression $(4,25)$

$$
C_{1}=\frac{i_{\mathrm{c}}}{v_{\mathrm{s}}}
$$

The related capacitance of fully oxidized polypyrrole from these experimental cyclic voltammograms have a value of about $35 \mathrm{mF} / \mathrm{cm}^{2}$ (compared to the usual $\mu \mathrm{F} / \mathrm{cm}^{2}$ values for the bare electrodes), which is similar to values obtained by other laboratories $(25,4)$. The origin of such large capacitance in polymer films has been discussed in detail by Tanguy et al. (26) and Mermilliod et al. (27) The behavior observed is similar to that of a capacitor with very high capacitance and is due to the highly porous structure of polypyrrole films (16).

The polypyrrole film is very stable between -0.8 and $+0.8 \mathrm{~V} v s$. SCE. It is possible to obtain more than $200 \mathrm{cy}-$ cles with no change in the coulombic capacity of the electrode. Extending the negative limit had little effect on the cyclic voltammogram characteristics. However, when the upper limit is taken to be more positive, there is a progres-

Table III. Electrochemical characteristics of the $1 \mu \mathrm{m}$ polypyrrole film

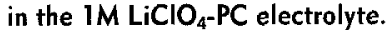

\begin{tabular}{lll}
\hline \multicolumn{1}{c}{ Scan rate $\left(v_{\mathrm{s}}\right)$} & \multicolumn{1}{c}{$10 \mathrm{mV} / \mathrm{s}$} & $20 \mathrm{mV} / \mathrm{s}$ \\
\hline Anodic peak potential $\left(E_{\mathrm{pa}}\right)$ & $-0.1 \mathrm{~V}$ & $-0.04 \mathrm{~V}$ \\
Cathodic peak potential $\left(E_{\mathrm{pc}}\right)$ & $-0.43 \mathrm{~V}$ & $-0.45 \mathrm{~V}$ \\
Anodic peak current density $\left(i_{\mathrm{pa}}\right)$ & $+0.95 \mathrm{~mA}$ & $+1.86 \mathrm{~mA}$ \\
Cathodic peak current density $\left(i_{\mathrm{pc}}\right.$ & $-0.72 \mathrm{~mA}$ & $-1.42 \mathrm{~mA}$ \\
Anodic charge density $\left(Q_{\mathrm{ca}}\right)$ & $+5.63 \mathrm{mC} / \mathrm{cm}^{2}$ & $+56.3 \mathrm{mC} / \mathrm{cm}^{2}$ \\
Cathodic charge density $\left(Q_{\mathrm{cc}}\right)$ & $-53.8 \mathrm{mC} / \mathrm{cm}^{2}$ & $-53.8 \mathrm{mC} / \mathrm{cm}^{2}$
\end{tabular}


Table IV. Fixed parameter values used for polypyrrole.

\begin{tabular}{ll}
\hline Faradaic charge of neutral polypyrrole $\left(Q_{\mathrm{f}, \mathrm{red}}\right)$ & $1.0 \times 10^{-5} \mathrm{C}_{\mathrm{cm}} \mathrm{cm}^{3}$ \\
Faradaic charge of oxidized polypyrrole $\left(Q_{\mathrm{f}, \mathrm{oxd}}\right)$ & $120.0 \mathrm{C} / \mathrm{cm}^{3 \mathrm{a}}$ \\
Porosity of neutral polypyrrole $\left(\epsilon_{\mathrm{red}}\right)$ & $1.0 \times 10^{-2}$ \\
Porosity of oxidized polypyrrole $\left(\epsilon_{\text {oxd }}\right)$ & $1.0 \times 10^{-3}$ \\
Double layer constant $\left(a^{*}\right)$ & $2.8 / \mathrm{V}^{\mathrm{a}}$ \\
Zero charge potential $\left(\eta_{\mathrm{pzc}}\right)$ & $-0.3 \mathrm{~V}(\mathrm{vs} . \mathrm{SCE})$ \\
Exponent on porosity term $(\mathrm{ex})$ & $0.5^{\mathrm{a}}$ \\
Exchange current density $\left(a i_{\mathrm{o}, \mathrm{ref}}\right)$ & $10.0 \mathrm{~A} / \mathrm{cm}^{3 \mathrm{a}}$ \\
Anodic transfer coefficient $\left(\alpha_{\mathrm{a}}\right)$ & $0.7^{\mathrm{a}}$ \\
Cathodic transfer coefficient $\left(\alpha_{\mathrm{c}}\right)$ & $0.3^{\mathrm{a}}$ \\
Open-circuit potential $\left(U_{\mathrm{ref}}\right)$ & $3.087 \mathrm{~V}(\mathrm{vs} . \mathrm{Li})$ \\
Number of electron $(n)$ & 1 \\
\hline
\end{tabular}

*Estimated values.

sive loss of capacity and film deterioration takes place after a few cycles.

Simulated results.-The simulated cyclic voltammograms for the polypyrrole film can be obtained by using the model presented in Table I, the operating conditions given in Table II, and fixed parameter values given in Table IV as shown in Fig. 4. The estimated value of each parameter in Table IV is obtained by comparison between experimental and simulated cyclic voltammograms and is discussed in detail later.

The current density relative to the projected electrode area, $i$, are obtained by integrated the local transfer current per unit volume $(\alpha j)$ over the porous polypyrrole electrode region

$$
i=\int_{y=0}^{y=y_{\mathrm{pp}}} a j d y
$$

It is noted that the value of the current density should be equal to the superficial current density in the solid phase $\left(i_{1}\right)$ at the current collector/polypyrrole electrode interface $(y=0)$

$$
i=\left.i_{1}\right|_{y=0}
$$

This is because all of the current enters (reduction) or leaves (oxidation) the cell via the current collector.

As discussed earlier, the current density in the cyclic voltammogram of the polypyrrole film consists of two distinctive components: faradaic current density caused by the electrochemical reaction and capacitive current density caused by the double layer within the porous polypyrrole film, $i_{\mathrm{f}}$ and $i_{\mathrm{c}}$. These are obtained by integrating the local faradaic and capacitive transfer currents per unit volume $\left(a j_{f}\right.$ and $\left.a j_{c}\right)$ over the porous polypyrrole electrode region (see Eq. [2]). A typical cyclic voltammogram and its components of $1 \mu \mathrm{m}$ polypyrrole film at a scan rate of

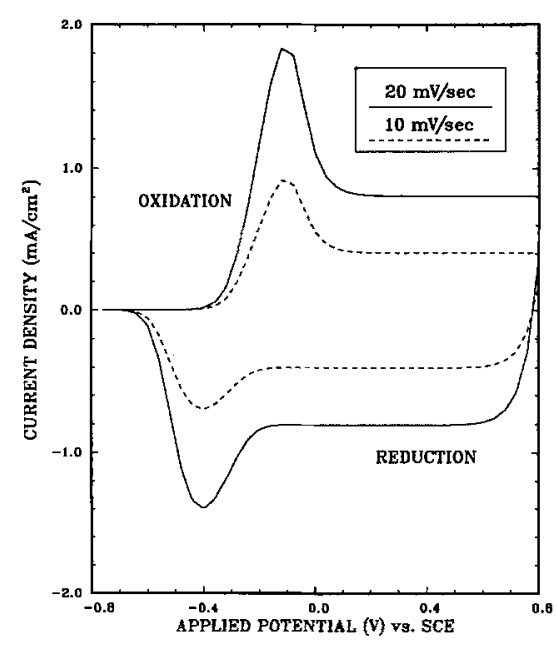

Fig. 4. Simulated cyclic voltammograms for a $1 \mu \mathrm{m}$ polypyrrole film in $1 \mathrm{M} \mathrm{LiClO}_{4}-\mathrm{PC}$ electrolyte at scan rates of 10 and $20 \mathrm{mV} / \mathrm{s}$.

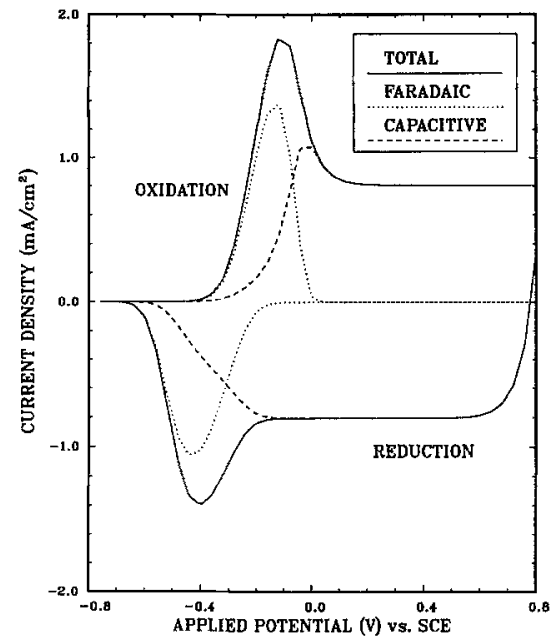

Fig. 5. Decomposition of a cyclic voltammogram into its two components, the faradaic and capacitive current densities, at a scan rate of $20 \mathrm{mV} / \mathrm{s}$.

$20 \mathrm{mV} / \mathrm{s}$ are presented in Fig. 5 as a function of the applied potential.

At potentials negative of $-0.4 \mathrm{~V}$, the entire polypyrrole electrode is in a fully neutral nonconducting state. For the anodic sweep of potential (increasing potential), neutral polypyrrole starts to converge to an oxidized conducting state at potentials positive of $-0.4 \mathrm{~V}$. The oxidation yields the consumption of both faradaic and capacitive charges within polypyrrole film. The faradaic current density $\left(i_{f}\right)$ initially increases with time because of the increasing driving force (applied potential), then decreases because of the limited electroactive area (neutral polypyrrole sites) and the concentration of counterion within the polymer film as the polypyrrole electrode is significantly oxidized. However, the capacitive current density $\left(i_{c}\right)$ increases continuously with time until the polypyrrole electrode is fully oxidized. At potentials positive of $+0.2 \mathrm{~V}$, the oxidation reaction is complete, and the entire polypyrrole electrode is in its fully oxidized conducting state. That is, the current density is entirely dominated by the double layer effect because no more oxidation of the polypyrrole can occur. The related capacitance $\left(C_{1}\right)$ of fully oxidized polypyrrole from these simulated cyclic voltammograms has a value of about $38 \mathrm{mF} / \mathrm{cm}^{2}$ and is well matched with that obtained from experiment.

When the scan is reversed in the cathodic direction (decreasing potential), the pure capacitive current density immediately changed sign. Oxidized polypyrrole starts to converge to the neutral state at potentials negative of $+0.2 \mathrm{~V}$ and yields decreasing faradaic and capacitive charges. At a potential $-0.6 \mathrm{~V}$, the entire polypyrrole electrode is again in its fully neutral state.

Dependent variables profiles.-The dynamic profiles of the dependent variables in the porous polypyrrole electrode region at a scan rate of $20 \mathrm{mV} / \mathrm{s}$ are shown in Fig. 6 through 8 as function of applied potential $(E)$ and position (y). In the position coordinate, $y=0$ represents the platinum current collector side and $y=1$ represents the electrolyte diffusion layer side as shown in Fig. 2.

The dynamic concentration profiles of the counterion $\left(\mathrm{ClO}_{4}^{-}\right)$within the porous polypyrrole electrode region at a scan rate of $20 \mathrm{mV} / \mathrm{s}$ are shown in Fig. 6. The concentration was made dimensionless relative to its reference concentrations $\left(c_{-}\right.$, ref $)$. It is noted that the concentration profiles of cation $\left(\mathrm{Li}^{+}\right)$have similar distributions because of electroneutrality.

Initially, the concentration of the counterion is uniform throughout the cell at the reference concentration $\left(c_{-, \mathrm{ref}}\right)$. For anodic scan, anions $\left(\mathrm{ClO}_{4}^{-}\right)$are consumed at the porous polypyrrole electrode region because of the oxidation of neutral polypyrrole and the increase of double layer charge. The counterion $\left(\mathrm{ClO}_{4}^{-}\right)$is transported from the bulk to the porous electrode region where it diffuses and $\mathrm{mi}$ - 


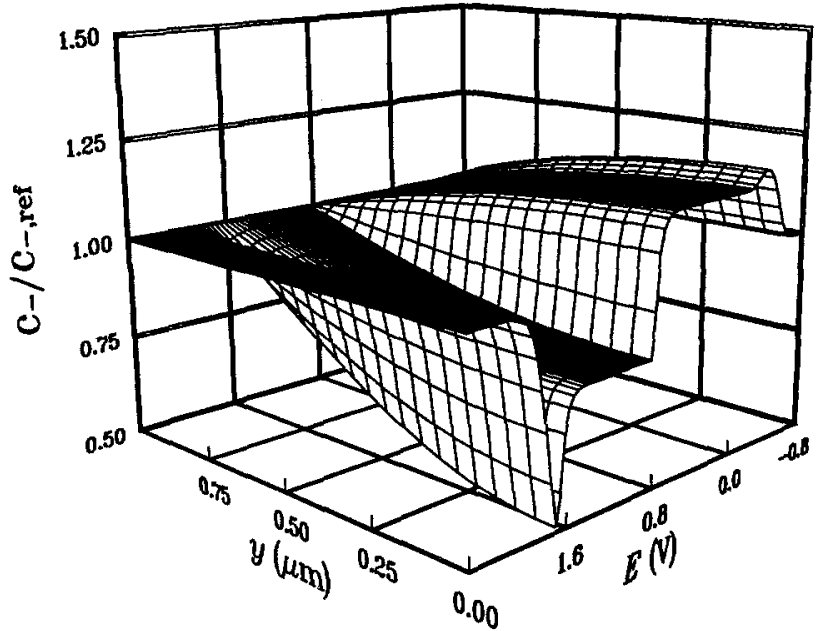

Fig. 6. Dimensionless concentration profiles of a counterion $\left(\mathrm{ClO}_{4}^{-}\right)$ within polypyrrole electrode region at a scan rate of $20 \mathrm{mV} / \mathrm{s}$.

grates to electroactive sites within the porous region. After polypyrrole has been fully oxidized, the concentration distribution within the porous polypyrrole electrode region bounced back to a certain equilibrium state. This is because no more oxidation of polypyrrole occurs and counterions are consumed by double layer charge only.

For cathodic scan, the oxidized polypyrrole sites are reduced and the opposite phenomena occurred. Anions $\left(\mathrm{ClO}_{4}^{-}\right)$are produced within the porous polypyrrole electrode region because of reduction of oxidized polypyrrole and decrease of double layer charge. The counterion $\left(\mathrm{ClO}_{4}^{-}\right)$is transported from the porous electrode region to the bulk. Since the effective diffusivities of $\mathrm{Li}^{+}$and $\mathrm{ClO}_{4}^{-}$ within the porous layer are much smaller than the free stream diffusivity of these species, the concentration gradients within the porous region must be larger to make up for the slower movement of the ions.

Figure 7 shows the distribution of faradaic charge per unit volume consumed within polypyrrole electrode due to the electrochemical reaction at a sweep rate of $20 \mathrm{mV} / \mathrm{s}$. The faradaic charge per unit volume was made dimensionless by using the maximum faradaic charge value $\left(Q_{\mathrm{f}, \mathrm{xxd}}\right)$ as the reference point.

Initially, the polypyrrole electrode is in fully neutral state $\left(Q_{\mathrm{f}}=Q_{\mathrm{f} \text {,red }}\right)$ and is ready to be oxidized. For the anodic scan, the faradaic charge is accumulated throughout the polypyrrole electrode region by the electrochemical reaction. The faradaic charge accumulation in the outer layer of the polypyrrole electrode (electrolyte diffusion layer side) is faster because of the concentration gradient effect within the polypyrrole electrode as shown in Fig. 7. After

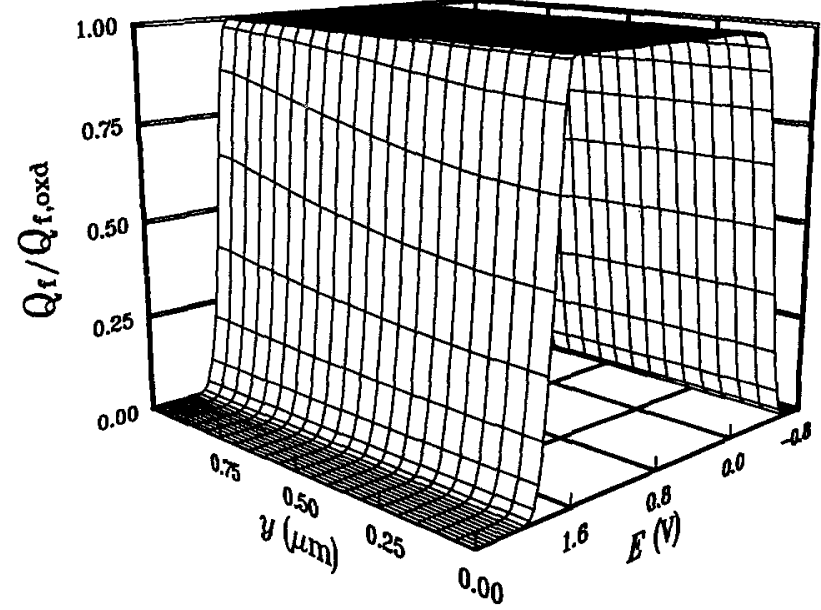

Fig. 7. Dimensionless faradaic charge profiles within polypyrrole electrode region at a scan rate of $20 \mathrm{mV} / \mathrm{s}$.

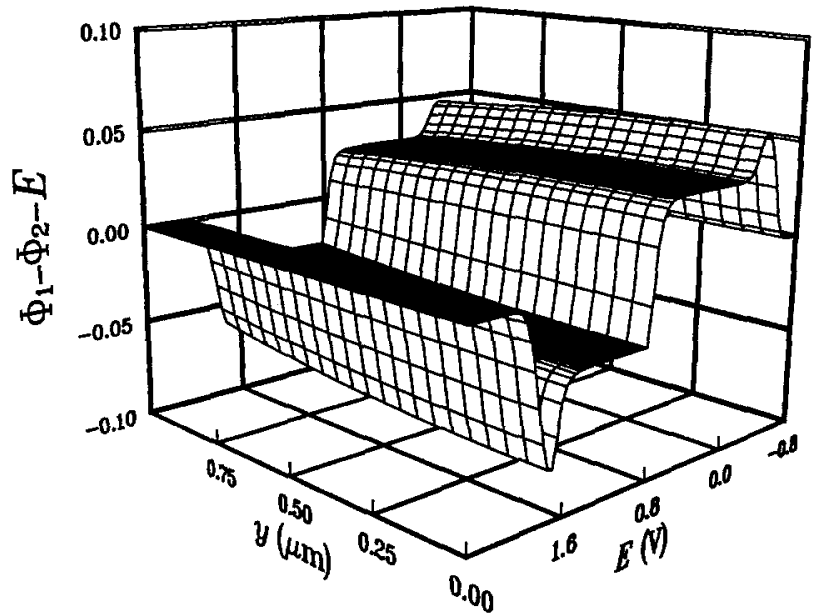

Fig. 8. Potential difference between solid and solution phases within polypyrrole electrode region at a scan rate of $20 \mathrm{mV} / \mathrm{s}$.

polypyrrole has been fully oxidized, the faradaic charge distribution becomes uniform at $Q_{\mathrm{f}}=Q_{\mathrm{f}, \text { oxd }}$. During reduction, the faradaic charge is withdrawn more slowly in the inner layer of the polypyrrole electrode (current collector side) because of the diffusion limitation. Note that charge accumulates rapidly throughout the entire electrode.

The electrochemical properties (such as porosity, conductivity, diffusivity, mobility, etc.) have similar distribution throughout the polypyrrole electrode region because of the assumption that these properties are proportional to the faradaic charge per unit volume consumed within polypyrrole electrode (21).

Figure 8 shows the distribution of the potential difference between solid and solution phases, the driving force for the electrochemical reaction and the double layer charge within the porous polypyrrole electrode region at a sweep rate of $20 \mathrm{mV} / \mathrm{s}$. For convenience, the potential difference is represented by $\Phi_{1}-\Phi_{2}-E$.

The potential difference increases with time indicating that the electrochemical reaction must proceed at a faster rate to compensate for the decreasingly available active surface area and reactive species in solution phase. It shows that the potential difference at the inner layer (current collector side) is higher because of diffusion limitation of counterion. The positive and negative values lead cathodic (reduction) and anodic (oxidation) reactions, respectively.

Sensitivity analysis.-Since the results predicted by the model depend on the physical and electrochemical parameters used, it is necessary to examine the sensitivity of the model predictions on these parameters and identify parameters which can be discarded from the further parametric analysis. If the model predictions are relatively insensitive to a parameter, then a fairly wide range of values for that insensitive parameter could be used without significantly affecting the predictions of the model. It is often the case that the more parameters that are estimated, the more uncertain are the estimates due to interaction between the parameters, poor sealing, and round-off errors (28).

The sensitivity coefficient of each parameter of interest, $S_{\mathrm{k}}$, can be determined from the changes in the predicted anodic current density response as follows

$$
S_{\mathrm{k}}=\sum_{E=-0.8}^{E=0.8} \frac{\Delta i_{\mathrm{a}}(E)}{m \Delta P_{\mathbf{k}}}
$$

where

$$
\begin{array}{ll}
\Delta i_{\mathrm{a}}(E) & =\left|i_{\mathrm{a}}(E)-i_{\mathrm{a}}^{*}(E)\right| \\
\Delta P_{\mathrm{k}} & =\left|\left(P_{\mathrm{k}}-P_{\mathrm{k}}^{*}\right) / P_{\mathrm{k}}^{*}\right| \\
i_{\mathrm{a}} & =\text { predicted anodic current density with } P_{\mathrm{k}} \\
i_{\mathrm{a}}^{*} & =\text { predicted anodic current densities with } P_{\mathrm{k}}^{*} \\
P_{\mathrm{k}} & =\text { perturbed value of parameter } \mathrm{k} \\
P_{\mathrm{k}}^{*} & =\text { reference value of parameter } \mathrm{k} \\
m & =\text { number of data points }
\end{array}
$$


Table V. Sensitivity analysis on various physical parameters.

\begin{tabular}{lc}
\hline Physical parameters & Sensitivity coefficient $\left(S_{\mathrm{k}}\right)$ \\
\hline Thickness of polypyrrole film $\left(\delta_{\mathrm{pp}}\right)$ & 0.68867 \\
Porosity of polypyrrole film $\left(\epsilon_{\mathrm{p}}\right)$ & 0.20020 \\
Thickness of diffusion layer $\left(\delta_{\mathrm{d} 1}\right)$ & 0.06169
\end{tabular}

Table VI. Sensitivity analysis on various electrochemical parameters.

\begin{tabular}{lc}
\hline \multicolumn{1}{c}{ Electrochemical parameters } & Sensitivity coefficient $\left(S_{\mathrm{k}}\right)$ \\
\hline Maximal Faradaic charge $\left(Q_{\mathrm{f}, \mathrm{xxd}}\right)$ & 0.66469 \\
Double layer constant $(a)$ & 0.52289 \\
Zero charge potential $\left(\eta_{\mathrm{pzc}}\right)$ & 0.49472 \\
Anodic transfer coefficient $\left(\alpha_{\mathrm{a}}\right)$ & 0.12216 \\
Exchange current density $\left(a i_{0, \mathrm{ref}}\right)$ & 0.08758
\end{tabular}

For convenience, only anodic (oxidation) current density responses are used to analyze the sensitivity of the model predictions here. Anodic current density responses shown in Fig. 4 and their conditions were used as the reference case. When an interesting parameter is perturbed slightly (i.e., multiplying by 1.05 to the reference value) while holding the values of all other parameters equal to that of the reference case, a new set of data of predicted anodic current density responses $\left(i_{\mathrm{a}}\right) v s$. applied potential $(E)$ is obtained. Then, the difference in the anodic current density responses between the reference and perturbed cases $\left(\Delta i_{\mathrm{a}}\right)$ is calculated at each potential interval and summed over the entire potential region used. The results of the sensitivity analysis are shown in Tables V and VI.

Table $\mathrm{V}$ shows the sensitivity of the anodic current density to the physical parameters, such as the porosity of the polypyrrole electrode $\left(\epsilon_{\mathrm{p}}\right)$, the thickness of the polypyrrole electrode $\left(\delta_{\mathrm{pp}}\right)$, and the thickness of the diffusion layer $\left(\delta_{\mathrm{d} 1}\right)$. The predicted anodic current density responses are found to be more sensitive to the electrode thickness $\left(\delta_{\mathrm{pp}}\right)$ and porosity $\left(\epsilon_{p}\right)$ than the thickness of the diffusion layer $\left(\delta_{d 1}\right)$. This is expected because the switching process of polypyrrole electrode is limited by the ion transfer rate within the porous structure. The effective diffusivities of $\mathrm{Li}^{+}$and $\mathrm{ClO}_{4}^{-}$within the porous layer are much smaller than the free stream diffusivity of these species. The fact that the current density responses are relatively insensitive to the thickness of the diffusion layer is comforting because it is usually much easier to measure the electrode thickness and porosity with a high degree of accuracy than is possible in measuring the diffusion layer. Note also that the porosity of the electrode has to be measured experimentally. A porosity value calculated theoretically from the material balance on the solid phase is not applicable because it ignores the existence of closed pores.

Table VI shows the sensitivity of the anodic current density to the electrochemical parameters describing the electrochemical reaction and the double layer effects on switching process. The most influential parameter is the maximal faradaic charge of polypyrrole $\left(Q_{\mathrm{f}, \mathrm{oxd}}\right)$. This is expected because the amount of electroactive material is proportional to this quantity. The double layer constant $\left(a^{*}\right)$ and the zero charge potential $\left(\eta_{\mathrm{pzc}}\right)$ are next followed by the anodic transfer coefficient $\left(\alpha_{a}\right)$ and the exchange current per unit volume $\left(a i_{0, \text { ref }}\right)$. The electrokinetic parameters describing the doping/undoping of polypyrrole have less influence than those describing the double layer effects. This could be due to the fact that polypyrrole has the large capacitive background current density as shown in Fig. 7 .

In a similiar manner, a sensitivity analysis could be used to determine the operating conditions where the sensitivity of a parameter is maximal as shown in Table VII. The effects of scan rate $\left(v_{\mathrm{s}}\right)$ on the performance of cyclic voltammogram are very significant. The oxidation and reduction peak height is proportional to the scan rate as is expected for a reversible surface process. However, the oxidation and reduction charge densities in each cycle is the same and does not depend on the scan rate. The effects of rotating speed $(\Omega)$ on the performance of cyclic voltammogram are not significant. Increasing rotating speed
Table VII. Sensitivity analysis on various operating conditions.

\begin{tabular}{lc}
\hline Operating conditions & Sensitivity coefficient $\left(S_{\mathrm{k}}\right)$ \\
\hline Potential scan rate $\left(v_{\mathrm{s}}\right)$ & 0.66468 \\
Disk rotation velocity $(\Omega)$ & 0.00002
\end{tabular}

causes more convective effects in the electrolyte diffusion layer. However, convective effect by rotating disk electrode is negligible within the porous polypyrrole electrode region.

Effects of parameters.-Many factors come into play when calculating the sensitivity coefficients. For example, the exchange current density and transfer coefficient strongly influence the initial slope in the cell current density. On the other hand, the maximum faradaic charge and double layer constant have more influence later when polypyrrole films are significantly oxidized. Thus, it is necessary to understand the detailed effects of each parameter, which is identified as relatively sensitive on model prediction. The effects of the maximal faradaic charge $\left(Q_{f_{0}, 0 x d}\right)$, the double layer constant $\left(\alpha^{*}\right)$, the anodic transfer coefficient $\left(\alpha_{a}\right)$, and the exchange current density $\left(\alpha i_{0, \text { ref }}\right)$, on the cyclic voltammograms are examined and estimated.

Figure 9 shows the effects of the maximum faradaic charge $\left(Q_{f, 0 x d}\right)$ in the cyclic voltammograms. This parameter affected both faradaic and capacitive current densities. The value does not influence the initial slope of the current density. However, the larger value of maximal faradaic charge yields higher and broader peak current densities, and higher background capacitive current density. This is because the amount of electroactive material is proportional to this value.

Figure 10 shows the effects of the double layer constant $\left(a^{*}\right)$ in the cyclic voltammograms. The region where polypyrrole is significantly reduced is not affected because this parameter only influences the double layer charging. Since the local capacitive transfer current per unit volume is proportional to this parameter (21), the larger value of double layer constant $\left(a^{*}\right)$ yields higher capacitive current density.

Figures 11 and 12 show the effects of the electrokinetic parameters describing the electrochemical reaction of polypyrrole. These parameters show significant effects in the region where polypyrrole is oxidizing or reducing. No effects are observed in the background capacitive current density. Figure 11 shows the effects of anodic transfer coefficient $\left(\alpha_{a}\right)$ in the cyclic voltammograms. This value strongly influences the shape of the peak current density. Increasing the anodic transfer coefficient $\left(\alpha_{a}\right)$ yields higher and narrower anodic

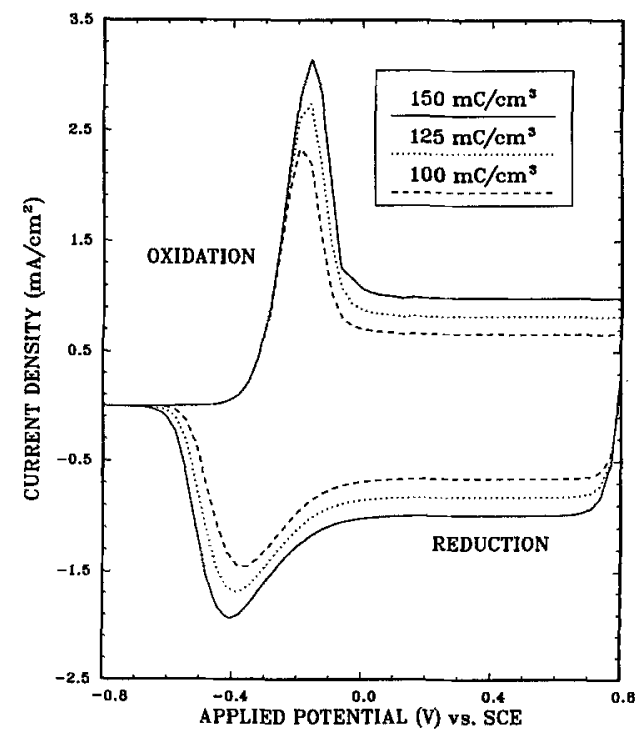

Fig. 9. The effects of maximal faradaic charge $\left(Q_{t, 0 x d}\right)$ on the cyclic voltammograms at a scan rate of $20 \mathrm{mV} / \mathrm{s}$. 


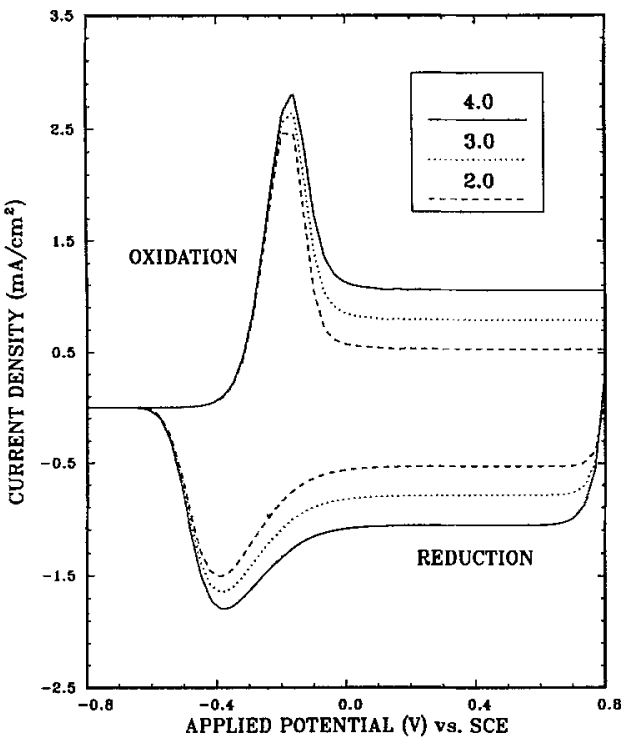

Fig. 10. The effects of double layer constant $\left(a^{*}\right)$ on the cyclic voitammograms at a scan rate of $20 \mathrm{mV} / \mathrm{s}$.

peak current density. The opposite is true for the cathodic direction because the sum of anodic and cathodic transfer coefficients $\left(\alpha_{\mathrm{a}}\right.$ and $\left.\alpha_{\mathrm{c}}\right)$ is set equal to 1 .

Figure 12 shows the effects of exchange current per unit volume $\left(a i_{o, \text { ref }}\right)$ in the cyclic voltammograms. This parameter shows a most significant influence in the peak current density. Increasing exchange current per unit volume yields both an increase in anodic and cathodic peak current densities and reducing potential difference between anodic and cathodic peak. This is because the electrochemical reaction rate is proportional to this value.

The value of each independent parameter discussed above has been estimated by comparing the peak and background current densities predicted by the model with the experimental results, and this has been summarized in Table IV. The dependent parameters (diffusion coefficients, mobilities, conductivities, etc.) can be calculated from the relationships given in the model development using the values of the independent parameters estimated here. For example, the effective diffusion coefficients of the counterion $\left(\mathrm{ClO}_{4}^{-}\right)$within the doped and undoped states of the polypyrrole film are $4.0 \times 10^{-11} \mathrm{~cm}^{2} / \mathrm{s}$ and $1.0 \times 10^{-9} \mathrm{~cm}^{2} / \mathrm{s}$, respectively. These values are smaller than those obtained from experimental measurements. This may be due to the large capacitive and uncompensated re-

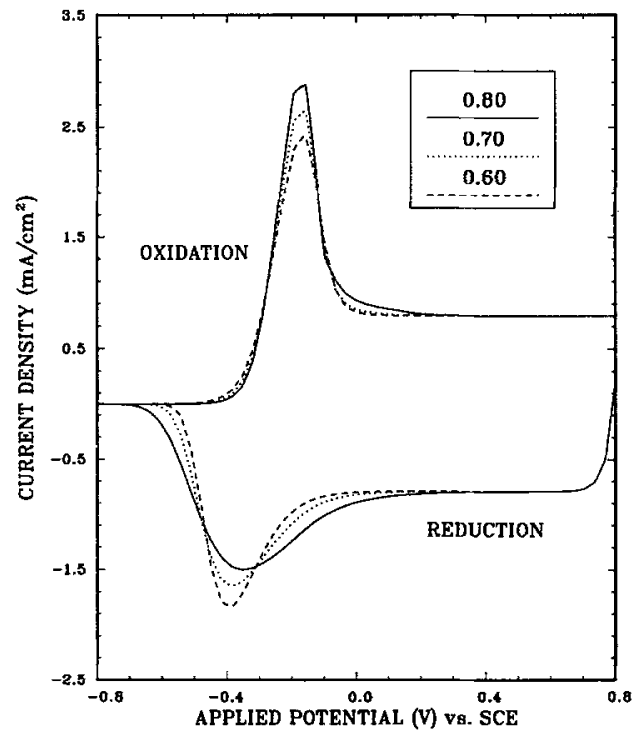

Fig. 11. The effects of anodic transfer coefficient $\left(\alpha_{a}\right)$ on the cyclic voltammograms at a scan rate of $20 \mathrm{mV} / \mathrm{s}$.

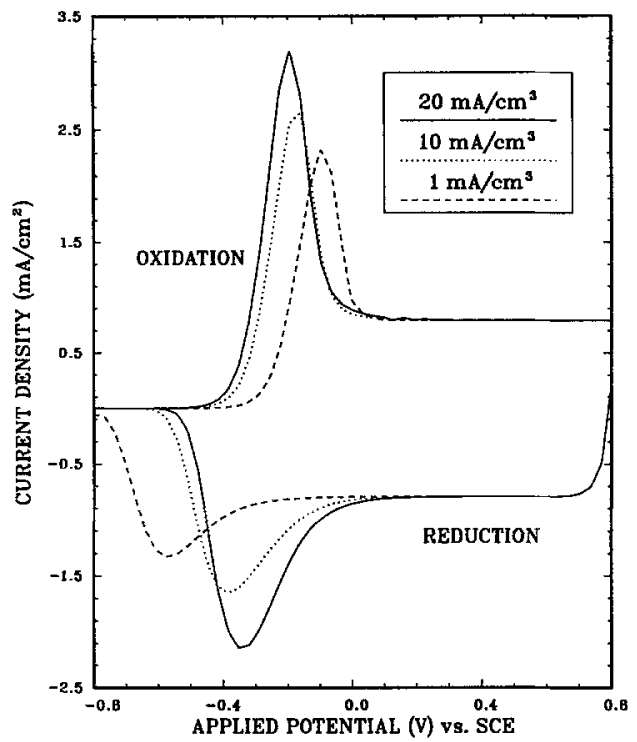

Fig. 12. The effects of exchange current per unit volume $\left(a i_{0, \text { ref }}\right)$ on the cyclic voltammograms at a scan rate of $20 \mathrm{mV} / \mathrm{s}$.

sistance effects in polypyrrole films which are not addressed properly in experiments.

\section{Conclusions and Recommendations}

The electronically conducting polypyrrole film has been synthesized electrochemically and used in cyclic voltammetry to study the electrochemical characteristics. The experimental results show that:

1. The simple one-step electrochemical oxidation of pyrrole monomer yields a flexible, metallic, and organic polymer film.

2. The polypyrrole film has a quasi-reversible switching behavior with large capacitive backgroun effects.

3. The switching process of the polypyrrole film is accompanied by distinctive color changes, brown-black at doped state and light yellow at undoped state.

4. The polypyrrole film can be cycled more than 200 times without significant loss of the coulombic capacity of the electrode.

These observations make polypyrrole a prospective candidate in the area of energy storage devices.

The mathematical model based on the porous electrode, dilute solution, and double layer theories, coupled to the Butler-Volmer-type rate expression has been developed to predict the cyclic voltammograms of a polypyrrole film under identical conditions of the experiments. The simulated results show that:

1. Despite the fact that the present model involves a number of simplifications such as the presumption that the electronic conductivity varies linearly with the doping level, a comparison of the simulated and experimental cyclic voltammograms shows quantitative agreement.

2. The modified Butler-Volmer-type rate expression can be applied for the quasi-reversible switching behavior or polypyrrole. This assumes that the appearance of the quasi-reversible peak in the cyclic voltammograms for conducting polymers is not necessarily evidence for the presence of an additional redox process.

3. The profiles of the dependent variables show that the switching process is governed by the availability of the counterion to the polypyrrole electrode and the amount of electroactive sites. Thus, the performance of the polypyrrole-based devices could be improved by physical modifications that increase the electroactive surface area and optimize the rate of ionic charge transport.

4. Sensitivity analysis shows that the parameters describing the double layer effects have more influence than those describing the electrokinetic process. This observation suggests that more emphasis should be placed on evaluating the capacitive effects affiliated with the doping state of polypyrrole. 
Better agreement between the simulated and experimental data will be obtained if different charge transport mechanisms are considered for the doping and undoping processes. In addition, the factors which determine the electrochemical characteristics of polypyrrole are the doping level and its functional relationship to the microscropic structure, conductivity, and capacitance. In the absence of any experimental or theoretical data, the presumptions used are adequate for these preliminary analysis. With pertinent experimental or theoretical data to quantify these factors, the model can be used, together with parameter estimation techniques, to determine the electrochemical characteristics of polypyrrole.

The model developed here can be modified to study cyclic voltammetric behavior of other conducting polymers, such as polythiophene, polyaniline, polycarbajole, etc., by simply adjusting the input parameters and their relationships. Also, the model can be extended to predict other electroanalytical techniques, such as ac impedance, chronocoulometry, and chronoabsorptometry. AC impedance can be useful in obtaining more details of the double layer effects.

\section{Acknowledgments}

It is gratefully acknowledged that this work was supported by a National Aeronautics and Space Administration grant NAG-9-173.

Manuscript submitted Nov. 1, 1990; revised manuscript received April 16, 1991.

Texas A\&M University assisted in meeting the publication costs of this article.

\section{LIST OF SYMBOLS}

A geometric electrode surface area, $\mathrm{cm}^{2}$

a specific surface area of polypyrrole film, $/ \mathrm{cm}$

$a^{\prime} \quad$ rotating disk electrode constant, 0.51023

$a^{*}$ double layer constant, $N$

$C_{1} \quad$ related capacitance of polypyrrole film

$c_{i} \quad$ concentration of species $\mathrm{i}, \mathrm{mol} / \mathrm{cm}^{3}$

$c_{i, \text { ref }}$ reference concentration of species $\mathrm{i}, \mathrm{mol} / \mathrm{cm}^{3}$

$D_{i} \quad$ diffusion coefficient of species $i, \mathrm{~cm}^{2} / \mathrm{s}$

$D_{i, p} \quad$ effective diffusion coefficient of species i within the polypyrrole film, $\mathrm{cm}^{2} / \mathrm{s}$

$E$ applied potential (potential difference between the current collector and reference electrode), $\mathrm{V}$

$E_{\text {neg }} \quad$ negative potential limit, V

$E_{\text {pa }} \quad$ anodic peak potential, $V$

$E_{\text {pc }} \quad$ cathodic peak potential, V

$E_{\text {pos }}$ positive potential limit, $V$

ex exponent on the porosity term, 0.5

F Faraday's constant, $96,487 \mathrm{C} / \mathrm{mol}$

$i$ current density based on projected electrode area, $\mathrm{A} / \mathrm{cm}^{2}$

$i_{\mathrm{a}} \quad$ anodic current density with perturbed value of $\mathrm{pa}-$ rameter $\mathrm{k}, \mathrm{A} / \mathrm{cm}^{2}$

$i_{\text {a }}^{*} \quad$ anodic current density with reference value of parameter $\mathrm{k}, \mathrm{A} / \mathrm{cm}^{2}$

$i_{\mathrm{e}}$ capacitive current density based on projected electrode area, $\mathrm{A} / \mathrm{cm}^{2}$

$i_{\mathrm{f}} \quad$ faradaic current density based on projected electrode area, $\mathrm{A} / \mathrm{cm}^{2}$

$i_{\text {o.ref }}$ exchange current density based on projected electrode area at reference concentrations, $\mathrm{A} / \mathrm{cm}^{2}$

$i_{\mathrm{pa}} \quad$ anodic peak current density based on projected electrode area, $\mathrm{A} / \mathrm{cm}^{2}$

$i_{\mathrm{pc}} \quad$ cathodic peak current density based on projected electrode area, $\mathrm{A} / \mathrm{cm}^{2}$

$i_{1} \quad$ superficial current density within the solid phase based on projected electrode area, $\mathrm{A} / \mathrm{cm}^{2}$

$\Delta i_{\mathrm{a}}$ difference of anodic current densities between reference and perturbed values of parameter $\mathrm{k}, \mathrm{A} / \mathrm{cm}^{2}$ local capacitive transfer current density within the polypyrrole film based on electroactive area, $\mathrm{A} / \mathrm{cm}^{2}$ local faradaic transfer current density within the polypyrrole film based on electroactive area, $\mathrm{A} / \mathrm{cm}^{2}$ local transfer current density within the polypyrrole film based on electroactive area, $\mathrm{A} / \mathrm{cm}^{2}$

$m$ number of data points for sensitivity analysis

$n$ number of electrons transferred for electrochemical reaction

$P_{\mathrm{k}} \quad$ perturbed value of parameter $\mathrm{k}$
$P_{k}^{*} \quad$ reference value of parameter $\mathrm{k}$

$\Delta P_{\mathrm{k}} \quad$ dimensionless difference between perturbed and reference values of parameter $k$

$Q_{\text {ca }} \quad$ anodic charge density of the polypyrrole film based on projected electrode area, $\mathrm{C} / \mathrm{cm}^{2}$

$Q_{c c} \quad$ cathodic charge density of the polypyrrole film

based on projected electrode area, $\mathrm{C} / \mathrm{cm}^{2}$

$Q_{\mathrm{f}} \quad$ local faradaic charge of the polypyrrole film per unit volume, $\mathrm{C} / \mathrm{cm}^{3}$

$Q_{\mathrm{f}, \mathrm{xxd}}$ faradaic charge of the fully oxidized polypyrrole film per unit volume, $\mathrm{C} / \mathrm{cm}^{3}$

$Q_{\mathrm{f} \text {,red }}$ faradaic charge of the fully neutral polypyrrole film per unit volume, $\mathrm{C} / \mathrm{cm}^{3}$

$R \quad$ universal gas constant, $8.3143 \mathrm{~J} / \mathrm{mol}-\mathrm{K}$

$S_{\mathrm{k}} \quad$ sensitivity coefficient of parameter $\mathrm{k}$

$s_{\mathrm{i}} \quad$ stoichiometric coefficient of species $\mathrm{i}$

$T$ absolute temperature $\mathrm{K}$

$t$ time, $s$

$u_{\mathrm{i}} \quad$ mobility of species i, mol-cm $\mathrm{cm}^{2} / \mathrm{J}-\mathrm{s}$

$u_{i, p} \quad$ effective mobility of species $i$ within polypyrrole film, mol-cm $\mathrm{cm}^{2} / \mathrm{J}-\mathrm{s}$

$v_{s} \quad$ scan rate, $\mathrm{V} / \mathrm{s}$

$y$ perpendicular distance from the platinum current collector/polypyrrole film interface, $\mathrm{cm}$

$y_{\mathrm{dl}} \quad$ position of the bulk solution in $y$ coordinate, $\mathrm{cm}$

$y_{\mathrm{pp}}$ position of the polypyrrole electrode/diffusion layer interface in $y$ coordinate, $\mathrm{cm}$

$z_{i} \quad$ charge number of species $i$

Greek

$\alpha_{a} \quad$ anodic transfer coefficient

$\alpha_{c} \quad$ cathodic transfer coefficient

$\delta_{\mathrm{d} 1} \quad$ thickness of the electrolyte diffusion layer, $\mathrm{cm}$

$\delta_{\mathrm{pp}} \quad$ thickness of the polypyrrole film, $\mathrm{cm}$

$\epsilon_{\mathrm{p}} \quad$ porosity of the polypyrrole film

$\epsilon_{\mathrm{oxd}} \quad$ porosity of the fully oxidized polypyrrole film

$\epsilon_{\text {red }} \quad$ porosity of the fully neutral polypyrrole film

$\eta \quad$ overpotential, $\mathrm{V}$

$\eta_{\mathrm{pzc}} \quad$ overpotential at the point of zero charge, $\mathrm{V}$

$\kappa$ free-stream solution conductivity, $/ \Omega-\mathrm{cm}$

$\kappa_{p} \quad$ effective solution conductivity within the polypyrrole film, $/ \Omega$-cm

$\theta \quad$ fractional doping level of polypyrrole film

$v \quad$ kinematic viscosity, $\mathrm{cm}^{2} / \mathrm{s}$

$\sigma_{\mathrm{p}}$ electronic conductivity of the polypyrrole film, $/ \Omega$-cm

$\Phi_{\text {ref }} \quad$ reference electrode potential, V

$\Phi_{1} \quad$ potential at the solid phase, $V$

$\Phi_{2} \quad$ potential at the solution phase, $V$

$\Omega \quad$ disk rotation velocity, $\mathrm{rad} / \mathrm{s}$

Subscript

$+\quad$ cation, $\mathrm{Li}^{+}$

- anion, $\mathrm{ClO}_{4}^{-}$

\section{REFERENCES}

1. T. Osaka, K. Naoi, S. Ogano, and S. Nakamura, This Journal, 134, 2096 (1987).

2. S. Panero, P. Prosperi, and B. Scrosati, Electrochim, Acta, 32, 1465 (1987).

3. A. Mohammadi, O. Inganäs, and I. Lundström, This Journal, 133, 947 (1986).

4. F. Trinidad, J. Alonso-Lopez, and M. Nebot, J. Appl. Electrochem, 17, 215 (1987).

5. H. Münstedt, G. Köhler, H. Möhwald, D. Naegele, R. Bitthin, G. Ely, and E Meissner, Synth. Met., 18, 259 (1987).

6. R. Noufi, D. Tench, and L. F. Warren, This Journal, 127, 1625 (1980).

7. F. F. Fan, B. Wheeler, A. J. Bard, and R. Nouf, ibid., 128, 2042 (1981).

8. T. Skotheim, I. Lundström, and J. Prejza, ibid., 128, 1625 (1981).

9. T. Skotheim, O. Inganäs, J. Prejza, and I. Lundström, Mol. Cryst. Liq. Cryst., 83, 329 (1982).

10. A. J. Frank and R. J. Honda, J. Phys. Chem., 86, 1933 (1982).

11. G. Cooper, R. Noufi, A. J. Frank, and A. J. Nozik, Nature, 295, 578 (1982).

12. A. F. Diaz, J. I. Castillo, J. A. Logan, and W. Lee, J. Electroanal. Chem., 129, 115 (1981).

13. A. F. Diaz and K. K. Kanazawa, Chem. Scr., 17, 145 (1981).

14. A. F. Diaz, M. Salmon, and J. Addy, in "Proceedings of 
the First European Display Research Conference," Munich, p. 111, VDE-Verlag GmbH, Berlin (1981).

15. M. Gazard, "Handbook of Conducting Polymers," Vol. 1, T. J. Skotheim, Editor, p. 673, Marcel Dekker, Inc., New York (1986)

16. R. A. Bull, F. F. Fan, and A. J. Bard, This Journal, 129, 1009 (1982)

17. P. Burgmayer and R. W. Murray, "Handbook of Conducting Polymers," Vol. 1, T. J. Skotheim, Editor, p. 507. Marcel Dekker, Inc., New York (1986)

18. G. B. Street, T. C. Clarke, M. Krounbi, K. K. Kanazawa, V. Lee, P. Pfluger, J. C. Scott, and G. Weiler, Mos Cryst. Liq. Cryst., 83, 253 (1982).

19. S. Asavapiriyanont, G. K. Chandler, G. A. Gunawardena, and D. Pletcher, J. Electroanal. Chem., 17\%, 229 (1984).
20. T. Yeu, T. V. Nguyen, and R. E. White, This Journal, 135, 1971 (1988).

21. T. Yeu and R. E. White, ibid., 137, 1327 (1990).

22. W. G. Cochran, Proc. Cambridge Phil. Soc., 30, 365 (1934).

23. M. H. Rogers and G. N. Lance, J. Fluid Mech., 7, 617 (1960).

24. F. Fan and A. J. Bard, This Journal, 133, 301 (1986).

25. S. Panero, P. Prosperi, S. Passerini, B. Scrosati, and D. D. Perlmutter, ibid., 136, 3729 (1989).

26. J. Tanguy, N. Mermilliod, and M. Hoclet, ibid., 134, 795 (1987).

27. N. Mermilliod, J. Tanguy, and F. Petiot, ibid., 133, 1073 (1986).

28. P. E. Gill, W. Murray, and M. H. Wright, "Practical Optimization," Academic Press, Inc., New York (1984).

\title{
Hydrous Oxide Film Growth on Amorphous Ni-Co Alloys
}

\author{
K. K. Lian ${ }^{*, 1}$ and V. I. Birss ${ }^{* *}$ \\ Chemistry Department, University of Calgary, Calgary, Alberta, T2N 1N4, Canada
}

\begin{abstract}
The electrochemical behavior of a $\mathrm{Ni}_{51} \mathrm{Co}_{23} \mathrm{Cr}_{10} \mathrm{Mo}_{7} \mathrm{Fe}_{5.5} \mathrm{~B}_{3.5}$ (weight percent) amorphous alloy ribbon has been investigated in alkaline solutions. When the metal is initially subjected to anodic potentials, an enriched $\mathrm{Cr}$ (and possibly B) surface layer is dissolved. Following this, a hydrous oxide film can be readily formed on the electrode surface by a continuous potential cycling method, to a thickness of up to ca. one micron. The film, which has an electrochemical signature which is very similar to the $\mathrm{Ni}$ (II)/Ni(III) transition, is electrochromic in nature and displays interference colors when still thin. The maximum growth rate of the film per cycle of potential has been found to be 0.15 to $0.20 \mathrm{mC} / \mathrm{cm}^{2}$, achieved by optimization of the magnitude and time spent at the upper and lower potential limits.
\end{abstract}

There has been a significant amount of interest in the electrochemical behavior of glassy alloys since the earliest reports of their superior corrosion resistance and interesting mechanical, electrical, and magnetic properties (1-10). The low corrosion susceptibility of these materials is not unexpected, due to the virtual absence of classical grain boundaries and other crystalline defects, as well as the frequent presence of elements such as $\mathrm{Cr}, \mathrm{Ti}, \mathrm{Nb}$, etc. ( 7 , 11-20), which are known to promote the formation of protective oxide films in most environments. There have also been numerous reports concerning the electrocatalytic nature of particular amorphous alloys toward reactions such as hydrogen and oxygen evolution (21-27) and the hydrogenation of carbon monoxide $(28,29)$. This is also rea sonable, as surface defect sites are known to play an im portant role in heterogeneous electrocatalytic reactions.

In the present study, an investigation of the electrochemical oxidation of an amorphous alloy, containing primarily $\mathrm{Ni}$ [51 weight percent (w/o)] and $\mathrm{Co}$ ( $23 \mathrm{w} / \mathrm{o}$ ), was undertaken. Alkaline solutions were utilized in order to minimize the dissolution of these metals, and oxide growth behavior was compared with that observed at polycrystalline $\mathrm{Ni}$ and Co electrodes. Polycrystalline Ni electrodes have been studied extensively in the past in alkaline solutions (30-39), due to their important application in secondary batteries, in which the principal reaction involves the $\mathrm{Ni}(\mathrm{II}) /(\mathrm{III})$ transition at ca. $1.4 \mathrm{~V}$ vs. RHE. Numerous investigations have indicated that $\mathrm{Ni}$ oxide films are hydrous in nature, and that they can be thickened by a particular continuous potential cycling regime (35-37) However, the resulting oxide and its growth behavior exhibit only some of the characteristics which are typical of other hydrous oxides, such as those formed at Ir (40-44), Rh (45), W (46), etc.

* Electrochemical Society Student Member.

** Electrochemical Society Active Member.

${ }^{1}$ Department of Metallurgy \& Materials Science, University of Toronto, Toronto, Ontario, M5S 1A4, Canada.
At a fresh polycrystalline Co electrode, several different oxidation/reduction steps can be seen in the first sweep of a CV experiment (47-49). With continued potential cycling, the buildup of a hydrous oxide film occurs readily $(47,48$, 50,51 , similar to the case at numerous other metals (40-46), where it is believed that new oxide film is formed during each excursion to positive potentials, while negative potentials are required in order to release the newly formed oxide from the metal surface to the overlying hydrous oxide film $(40,41)$. The principal electrochemical reaction [Co(III)/(IV)] occurs in the range of 1.0 to $1.5 \mathrm{~V}$ vs. RHE. Oxidized $\mathrm{Co}$ electrodes, as well as $\mathrm{Co} / \mathrm{Ni}$ oxide electrodes, have also been investigated (52-54) with respect to the kinetics of the oxygen evolution reaction (OER) at these materials.

The purpose of this research was to determine how the presence of both $\mathrm{Co}$ and $\mathrm{Ni}$, as well as several secondary elements ( $\mathrm{Cr}$, Mo, and $\mathrm{B}$ ) influence the nature of oxide growth and the properties of the resulting oxide film. Also, it was of interest to examine the impact of the amorphous structure of the substrate on the properties of the electrochemically formed oxide films. Both electrochemical and ex situ surface analytical techniques were employed in this work in an attempt to answer these questions.

\section{Experimental}

Cyclic voltammetry was carried out with the use of a Hokuto-Denko HA301 potentiostat and a Tacussel GSATP function generator, or with the EG\&G PARC $175 / 173 \mathrm{com}$ bination when infrared compensation was required. Either a HP 7045B XIY recorder or a Nicolet 3091 digital oscilloscope were employed to record the electrochemical data. The working electrode (WE) used in all of these experiments was a melt-spun $\mathrm{Ni}_{51} \mathrm{Co}_{23} \mathrm{Cr}_{10} \mathrm{Mo}_{7} \mathrm{Fe}_{5.5} \mathrm{~B}_{3.5}$ (composition given in terms of w/o) glassy alloy, provided by AlliedSignal Corporation in the form of a ribbon $25 \mathrm{~mm}$ wide 